\title{
walad: Feto ou Filho; A Restauração do Sentido Original de Gn 11:30
}

\author{
Suzana Chwarts
}

Resumo: Esta pesquisa focaliza o termo walad na caracterização de Sara como estéril em Gn 11:30 - wa tehi śarai 'aqarah 'ein lah walad - duas orações traduzidas universalmente como e Sara é estéril, não tem filho(s). A segunda oração foi considerada uma redundância e a palavra walad, um erro por parte do escriba que copiou as Escrituras.

No contexto de minha interpretação da narrativa patriarcal, walad é uma escolha deliberada e engenhosa por parte do redator. De forma alguma o termo está solto ou isolado no corpo da narrativa. Ao contrário; estabelece uma correspondência entre episódios, "um campo de força temático" 1 que delineia um ciclo de esterilidade intra-abraâmico, específico a Sara e Abraão, iniciado em Gn11:30 e concluído em Gn21:5, com o nascimento de Isaac.

walad com o sentido de feto - minha proposta de tradução - funciona como fio condutor da narrativa, interligando-se fonetica e semanticamente ao verbo lehiwaled ( nascer ) em Gn 17 e 21. Dessa forma, confere contornos específicos à narrativa, que evolui da imposssibilidade reprodutiva dos protagonistas ao cumprimento da promessa divina a Abraão e Sara .

Essa terminologia memorável encerra profundo valor teológico: ao assinalar a ausência de feto no útero de Sara e a impossibilidade de dois idosos gerarem, expõe a perspectiva humana em contraponto à natureza miraculosa dos desígnios divinos.

A pesquisa considera, ainda, a possibilidade que 'ein lah walad seja uma inserção sacerdotal num trecho javista .

Palavras - chaves: Bíblia hebraica - Matriarcas - Promessa Divina Esterilidade.

\footnotetext{
${ }^{1}$ Expressão utilizada por Robert Alter, em Guia Literário da Bíblia. São Paulo: Unesp, 1997; p.97.
} 


\section{walad: Feto OU FILHO; A RESTAURAÇÃO do SENTIDO ORIGINAL DE Gn 11:30.}

Sara, a matriarca de Israel, é introduzida na narrativa do livro do Gênesis no capítulo 11:30 de forma surpreendente - a ela não é atribuída nenhuma referência de parentesco; é simplesmente designada como a esposa que Abraão tomou para si.

A indefinição de sua identidade é suprimida por sua implacável caractrização no versículo seguinte: "watehi śarai 'aqarah, 'ein lah walad" - traduzido para todas as línguas como "e Sara é estéril; não tem filho(s)"

A primeira sentença é a forma narrativa que introduz o termo universalmente atribuído à fonte javista 'aqarah (estéril) e que irá caracterizar igualmente as matriarcas Rebeca e Raquel. Já a sentença 'ein lah walad é uma forma exclusivamente aplicada a Sara, sem paralelo na Bíblia Hebraica. ${ }^{2}$

A esterilidade de Sara, assim como a das outras matriarcas de Israel suscitou pouco interesse por parte de estudiosos de todos os tempos; aqueles que prestaram atenção no versículo discutiram essencialmente a relação de redundância ou complementaridade entre as orações.

C. Westermann afirma que as duas sentenças têm o mesmo sentido, opondose a B. Jacob, que atribui propósitos distintos para cada sentença: a primeira indicaria que o casamento não gerou filhos; e a segunda, que Sara, enquanto esposa, teve de seguir sem filhos.(Komm,1934,1974).

De acordo com M. Callaway, Gn11:30 é uma interpolação javista na relação genealógica sacerdotal de Gn $11 .{ }^{3}$ Uma informação solenemente inserida no contexto da genealogia familiar de Abraão reforçada com uma frase redundante: não tem filho. Ou rebento, na tradução de Chouraqui. ${ }^{4}$

Para Callaway, o emprego desta "redundância" é um sinal claro do autor de

\footnotetext{
${ }^{2}$ Westermann e Skinner chamam a atenção para 2Sm 6:23. O termo ocorre novamente, como ktiv, na sentença onde o narrador informa que Micol, filha de Saul, não teve filho até o dia de sua morte (ulemikhal bat ša'ul lo' hayah lah yaled 'ad yom motah). O mesmo paralelismo (sem a forma rara walad) ocorre, em contexto similar, em Jz13:2 (we'išto 'aqarah welo'yaladah) e em Is 54:1 (rani 'aqarah lo' yaladah). Westermann, Genesis. Minneapolis: Augsburg, 1981, p. 139.

${ }^{3}$ Callaway, Sing O’Barren One. Atlanta: Scholars Press, 1986; p. 20.

${ }^{4}$ Chouraqui traduz: para ela nada de rebento. Chouraqui, No principio, p.123. .
} 
que esse será um tema importante. ${ }^{5}$ E Chouraqui nota que ao utilizar walad, uma forma rara, ao invés da forma habitual, yeled, o autor está sublinhando a gravidade dessa esterilidade. ${ }^{6}$

H. Gunkel e seus seguidores consideraram walad um erro do escriba que copiou as escrituras, e que provavelmente influenciou a passagem em $2 \mathrm{Sm}$ $6: 23^{7}$, tendo como base do argumento o fato que no canaanita antigo a letra waw transformou-se em yod e que walad pertence às formas antigas nas quais o waw foi mantido.

Essa hipótese é rejeitada por Westermann, que conclui que Gn11:30 é uma forma lapidar, precisa, de um motivo popular da narrativa (a infertilidade da esposa), que ocorre em vários contextos, e que funciona geralmente como introdução ao relato. Em sua opinião, a sentença adquire maior relevo e força através do recurso literário do paralelismo, utilizado não apenas na poesia, como também na prosa bíblica.

Filho ou rebento; nenhuma tradução traz walad como feto.

O termo ugarítico waladu significa offspring. ${ }^{8} \mathrm{O}$ Dictionary of Classical Hebrew $^{9}$ traz o sentido explícito de feto; walad, com esse sentido, aparece também nos manuscritos de Qumeran (4QMMTc 1.1:37) - hawalad šebeme 'ei 'imo (o feto ( que está) nas entranhas de sua mãe) ${ }^{10}$

Como na Bíblia Hebraica o sentido da palavra é estabelecido pelo contexto, walad como feto faz todo sentido, enquanto yeled = criança, abarca uma

${ }^{5}$ Callaway, op. cit., p. 21.

${ }^{6}$ Chouraqui, op. cit., p.123. Westermann crê que walad é uma forma antiga para "filho" que caiu em desuso e foi conservada na fórmula de Gn11:30. Westermann, op. cit., p.139. Na Bíblia Samaritana, lê-se yeled, ao invés de walad.

${ }^{7}$ Westermann, op. cit., p.139.

${ }^{8}$ Westermann, op. cit., p. 133.

${ }^{9}$ The dictionary of classical hebrew, vols. I- V, Clines (ed).

${ }^{10}$ nossa tradução. 
existência consolidada, desde o nascimento até a juventude. ${ }^{11}$

Em minha leitura do texto, walad encerra algumas das propriedades mais significativas do conceito bíblico da esterilidade, tais como insubstancialidade e potencialidade.

walad é, sem dúvida, um vocábulo especial e raro. É também um termo original, solene, que tem a propriedade de transformar uma sentença "redundante" em memorável.

N. Sarna afirma que o termo hebraico 'aqarah significa "sem filhos" (“childless"), mas não necessariamente infértil. ${ }^{12} \mathrm{E}$ muito embora não teça comentário algum sobre a segunda sentença, a sua afirmação sobre 'aqarah vem corroborar minha impressão de que 'ein lah walad tem uma função específica, e não complementar, na caracterização de Sara, enfatizando a ausência de feto em seu ventre.

R. Alter, ao abordar a questão do significado do detalhe literal na narrativa bíblica, chama a atenção para o fato de que geralmente trata-se de um termo estranho, gratuito, para o qual nenhuma explicação é oferecida, e para o qual as narrativas circundantes não proporcionam chaves temáticas óbvias. ${ }^{13}$

Uma espécie de alien literário sem nenhum propósito evidente, a ponto de ser considerado um erro de escriba; e embora Alter não faça nenhuma referência a walad, suas observações caem como uma luva para o termo em questão.

Segundo Alter, o objetivo do detalhe, às vezes espantoso em sua concretitude, é implicar direção e sentidos além daqueles declarados explicitamente, ${ }^{14}$ ou seja, uma perspectiva.

\footnotetext{
${ }^{11}$ Schökel, Dicionário bíblico hebraico-português.

${ }^{12}$ Sarna, Genesis, p.87.

${ }^{13}$ Alter, "Especificação narrativa e sentido literal na Bíblia", em Simpósio de cultura oriental e cultura ocidental: projeções, Berezin (coord.), pp.94-97.
}

${ }^{14}$ Alter, op. cit., p. 94.

${ }^{15}$ Expressão utilizada por Robert Alter, op. cit., p. 97.

${ }^{16}$ Da raiz $y l d$, geralmente empregado no feminino, com o sentido de "dar à luz". Brown, Driver e Brigs. 
No contexto de minha interpretação da narrativa patriarcal, walad é uma escolha deliberada e engenhosa por parte do redator. De forma alguma o termo está solto ou isolado no corpo da narrativa. Ao contrário: walad estabelece uma correspondência entre episódios, "um campo de força temático" ${ }^{15}$ que delineia um ciclo de esterilidade intra-abraâmico, específico a Sara e Abraão, iniciado em Gn11:30 e concluído em Gn21:5, com o nascimento de Isaac.

\section{O SENTIDO DE WaladNA INTRODUÇÃO}

A sentença " "ein lah walad" confere uma dimensão específica à esterilidade esquemática estabelecida pela sentença anterior, "watehi śarai 'aqarah". Ela vem realçar a percepção da ausência, do vazio do ventre de Sara, de sua incapacidade biológica de gerar um feto. Antes de mais nada, é uma forma de desnudá-la e degradá-la.

$\mathrm{Na}$ introdução à narrativa, walad enfatiza um aspecto relevante da caracterização de Sara no ciclo de Abraão: a indefinição de sua identidade ( quem é seu pai ? ela é irmã de Abraão, ou não ?) .

Cada um dos elementos dessas duas sentenças introdutórias contribui para delinear Sara em termos de caos:

watehi (qualidade de ser estática, retentora)

'aqarah (desarraigada/impotente/infecunda)

'ein lah (desprovida de ascendência, descendência e status)

walad (indeterminação/informidade)

A ausência de feto é a marca distintiva da esterilidade de Sara, matriarca ancestral de Israel. Ao empregar um termo não-coloquial como walad, o narrador amplia a imprevisibilidade da informação sobre sua esterilidade e o mistério que envolve esse estado inusitado, no qual se inscreve a matriarca.

Por um lado, Sara - mulher, sem ascendência, incapaz de gerar filhos - é um balde de água fria na genealogia exclusivamente masculina da linhagem de Taré, pai de Abraão.

A ênfase na negação - "estéril; não tem filhos" - constrói uma oposição direta à enfática relação de descendentes da lista genealógica. walad contrasta com a terminologia sólida de reprodução empregada na genealogia (holid, yoled =gerar, dar à luz $)^{16}$ e com o alicerce de todo o Gênesis (toldot, literalmente 
nascimentos, com o sentido de genealogia). ${ }^{17}$

Enquanto toldot constituiu o pilar da narrativa de Gn11, walad introduz o elemento da não-permanência e da insubstancialidade.

Por outro lado, a esterilidade de Sara extrapola os limites de uma "tragédia pessoal" e assume contornos corporados: o seu ventre estéril é o ponto de partida da história formativa de Israel, em estado embrionário em todo o ciclo partriarcal.

Estrategicamente localizada entre a genealogia (contida em Gn11) e a narrativa (que se desenvolve a partir de Gn12), a informação sobre a esterilidade de Sara em Gn 11:30 localiza-se também entre um gênero universal de história (capítulos 1-11 do Gênesis) e outro, ancestral, exclusivo de Israel, cuja história começa a ser criada a partir daquele momento.

'ein lah walad nos insere em uma dimensão totalmente nova, uma criação inusitada a partir de uma esterilidade divina e implacável.

Há uma grande diferença entre não ter filho e não ter feto. yeled ( criança ) como seria de se esperar, é uma unidade de parentesco, um filho concreto de pai e mãe. Já walad não é uma referência de parentesco, mas apenas uma potencialidade, e, ao contrário de yeled, possui propriedades de indeterminação e insubstancialidade.

O seu emprego suscita a idéia de início de desenvolvimento de um organismo rudimentar, indiferenciado, semi-vivo/ semi-morto, no meio intrauterino, que, por sua vez, está associado diretamente com a morte e o vazio.

walad representa o potencial evolucionário que ainda não foi externalizado e fixo na estrutura. Situa a narrativa entre morte e nascimento num estado

${ }^{17}$ Fokkelman afirma que as toldot propiciam uma estrutura sólida que sustenta e articulam meticulosamente as várias seções do Gênesis. Fokkelman, "Gênesis", em Guia Literário da Bíblia, p. 55.

${ }^{18}$ A bênção combina uma mensagem híbrida de fertilidade e status de matriarca.

19 'ezer kenegdo - 'ezer, cuja raiz significa ajudar, combinada com a preposição neged, literalmente "contra, em oposição a".

${ }^{20} \mathrm{Dt12:23:} \mathrm{"o} \mathrm{sangue} \mathrm{é} \mathrm{vida".}$

21 “Murchar, estar em farrapos “ é uma expressão empregada por Sara em Gn 18:12 ('aharei beloti). Segundo Westermann, o verbo do radical blh = to be worn out é utilizado para roupas em Js 9:13, para ossos que se tornam secos no S132:3, e apenas em Gn18:12 para se referir a uma mulher. Westermann, op. cit., p.281. Sarna comenta ainda que 'ednah significa "hidratação, umidade abundante" e que se opõe diretamente a "murchar". Ibid., p. 130.

${ }^{22}$ Erikson, Erik e Joan, "Womanhood and the Inner Space", em Identity: youth and crisis, pp. 261320. Citado por Doyle no artigo "Women and Religion: Psychological and Cultural Implications", em Ruether,Rosemary Radford ( ed.), Religion and sexism, pp.27-28. 
intermediário, liminar, que é a própria esterilidade (com seus sentidos entrelaçados de infecundidade-desenraizamento-impotência) da qual se sabe que, ao menos no relato bíblico, jamais é definitiva.

A terminologia reprodutiva utilizada na caracterização de Sara demonstra como a mulher é conceituada culturalmente a partir de seus poderes reprodutivos.

$\mathrm{Na}$ instituição do matrimônio, por exemplo, os atributos femininos são enfatizados através das propriedades reprodutivas, como na bênção a Rebeca $\left(\mathrm{Gn24:60),}{ }^{18}\right.$ e não através de características sociais e de afiliação, como exemplificado no conceito primordial "uma auxiliar que lhe corresponda" (Gn $2: 18){ }^{19}$

$\mathrm{Na}$ natureza reprodutiva interna da mulher estão embutidos os elementos de oposição binária através da qual grande parte do pensamento israelita se estrutura: vida $\mathrm{x}$ morte; fertilidade $\mathrm{x}$ infertilidade; pureza $\mathrm{x}$ impureza; favor divino $\mathrm{x}$ desfavor e tabu.

De um lado: fertilidade, capacidade de nutrir dentro e fora do útero, de dar à luz, a própria posse de um útero e toda sua simbologia incubadora; de outro: infertilidade cíclica, com perda de sangue (substância comumente associada à vida $)^{20}$ e tabus associados a esse sangue.

No caso dos israelitas, que convivem simultaneamente com o deserto e a terra arável, essa dicotomia é ainda mais perceptível. O humano e a terra estão intrinsecamente ligados por uma relação indissolúvel de ação e retribuição. Uma das elaborações mais complexas do pensamento hebraico é a maneira como o humano polui a terra com suas transgressões aos preceitos divinos, tornando-a impura e infértil - duas atribuições sócio-religiosas da mulher menstruada na sociedade israelita antiga.

Retomando a narrativa bíblica, vê-se que a idéia do útero vazio de Sara é dominante. Mesmo quando é Abraão, e não Sara, quem se lamenta, a informação de fundo é a de que Abraão não tem descendência, pois Sara não pode ter filhos.

Muito embora a natureza dessa pesquisa não envolva abordagem psicanalítica, creio ser especialmente significativa a associação que fazem Erik e Joan Erikson entre o útero e a noção de vazio interior. Os Eriksons afirmam que o vazio é uma forma própria de perdição feminina, uma experiência standard feminina, um senso especial de solidão ligado à sua morfologia reprodutiva, à centralidade do espaço produtivo interno de seu corpo, ou seja, o seu útero. 
Segundo sua análise, a importância das promessas e limitações do espaço produtivo interno expõe a mulher a um senso específico de solidão - o medo de ser deixada vazia ou desprovida de tesouros, ou de permanecer incompleta, ou murchar. ${ }^{21}$ Suas observações clínicas sugerem que, na experiência feminina, o espaço interior é o centro do desespero até quando é o próprio centro da realização potencial. ${ }^{22}$

E, no entanto, esse vazio interior - tipicamente feminino, expresso em " 'ein lah walad" - cria um elo de afinidade entre Sara e Abraão. Abraão define a si próprio em termos de vazio e privação: Gn 15 estabelece a equivalêcia direta entre feto - que Sara não tem - e descendência ( zera') que D'não deu a Abraão.

\section{A SEGMENTAÇÃO DO TEXTO}

Os capítulos que tratam da questão de reprodução e descendência representam Abraão e Sara como uma unidade. Na minha leitura, este é um recurso para enfatizar a descendência cognática da linhagem ancestral e para enaltecer a origem desta linhagem como fruto da vontade divina, e o emprego da terminologia reprodutiva confere contornos e coerência a este sistema ideológico. $^{23}$

A segmentação dessa terminologia em três blocos distintos nos permite divisar distintas estruturas de pensamento na narrativa:

Bloco I: walad, ywaled, behiwwaled $-{ }^{24}$ terminologia utilizada na introdução à esterilidade de Sara e no desfecho da trama. Estabelece um ciclo temático intra-abraâmico (particularização).

Bloco II: formas verbais do radical yld ( dar à luz) - terminologia corriqueira; confere unidade às várias estórias (generalização).

Bloco III: 'asar e latet (interditar, outorgar ) - linguagem especial, de cunho teológico. É utilizada na introdução à esterilidade de Abraão e de Sara, na promessa divina e no desfecho (deificação).

\footnotetext{
${ }^{23}$ A maior parte das sentenças que fazem referência à esterilidade (Gn 11:30;15:1; 16:1; 16:2) no decorrer da narrativa é caracterizada pelo emprego do pronome possessivo, sempre associado a uma partícula de negação que enfatiza o ser e a noção de particularidade do desígnio divino (diretamente direcionado a ele), ao mesmo tempo em que funde Abraão e Sara numa só entidade.

${ }^{24}$ na tradução perde-se a conecção fonética dos termos - feto, nascerá, ao nascer.
} 
O Bloco I é o foco da presente pesquisa e é pontuado por 3 estágios na narrativa :

1. narrador (Gn 11:30) ...'ein lah walad ... (ela não possui walad $)^{25}$

2. Abraão (Gn 17:17)..haleben me'ah šanah ywaled?( nascerá a um homem de 100 anos ? $)^{26}$

3. narrador (Gn 21:5) 'avraham ben me'at šanah behiwwaled lo et yshaq bno ( Abraão tem cem anos ao nascer-lhe Isaac seu filho $)^{27}$

Do ponto de vista gramatical, ywaled é a forma corriqueira do radical yld (conjugado no modo nifal).

É o contexto que confere a esta forma seu valor especial: esta ocorre apenas duas vezes no ciclo de Abraão e Sara $^{28}$ e seu sentido se opõe ao sentido usual de $y$ waled e a todas as outras formas de dar à luz, nascer - como nolad, holid, yalad, yoled.

Enquanto todas afirmam o ato de gerar, ywaled, em Gn17:17 questiona a capacidade de gerar.

Descortina-se uma lógica sutil na composição desse ciclo: isso ocorre por meio de elementos diferenciadores que exaltam a qualidade dos eventos . Eventos corriqueiros em outros contextos, mas, nesta instância, absolutamente singulares.

A interseção entre walad-ywaled-behiwwaled induz à percepção de uma conexão temática (a impossibilidade biológica e pessoal de gerar), sonora (de grande importância para uma audiência) e imagética (fixa, em primeiro plano, logo no início da narrativa).

Em Gn17:17, Abraão se pergunta:

...haleben me'ah šanah ywaled we'im śarah habat tišim teled?( nascerá a um homem de 100 anos? e Sara, de 90 anos dará à luz? $)^{29}$

\footnotetext{
${ }^{25}$ nossa tradução .

${ }^{26}$ idem.

${ }^{27}$ idem .

${ }^{28}$ E mais outras duas vezes em todo o Livro do Gênesis - Gn 4:15, na lista genealógica da linhagem de Caim, e em Gn46:14, na genealogia de José. Em ambas as ocorrências, a forma é waywaled e o sentido é o mesmo de nolad.

${ }^{29}$ nossa tradução.
} 
Novamente Abraão duvida da promessa divina; a primeira vez ocorre em Gn 15:3 - ao questionar o que Deus pode lhe dar, já que ele se vai pela vida ou da vida desprovido, sem filhos ( holekh 'ariri ).

Em Gn 17 Abraão expressa sua dúvida questionando a própria capacidade reprodutora aos cem anos de idade. Esse versículo traz a construção de uma questão dupla, que restaura a marca distintiva de Abraão e Sara na narrativa: a sua unidade, baseada em sua esterilidade comum (que foi seccionada pela produção de semente de Abraão: Ismael). Dois elementos são enfatizados: idade biológica $\mathrm{x}$ capacidade biológica de gerar.

Em Gn 21:5, o narrador enfatizará o cumprimento pontual da promessa através da repetição: behiwwaled lo 'et yshak bno ( ao nascer-lhe Isaac seu filho $)^{30}$

É importante ressaltar que os outros nascimentos, o de Ismael, por exemplo, são descritos por intermédio do mesmo radical $y l d$, mas a terminologia utilizada é o usual "nolad", também empregado em relação a Isaac em Gn21:3.

Significativamente o v.5 (que contém ywaled) vem imediatamente após a circuncisão de Isaac por seu pai, e sua categorização como portador da aliança divina. Logo após, no v.8, Isaac será chamado yeled.

$\mathrm{O}$ emprego de ywaled age como fio condutor das duas polaridades do pensamento bíblico. De um lado, o homem, no exercício de seu conhecimento e percepção de sua natureza biológica, naturalmente duvida. A Abraão é lícito duvidar e crer, ao mesmo tempo. ${ }^{31}$ Do outro lado, está a qualidade absoluta da ação divina: livre, desconectada das possibilidades e impossibilidades da natureza humana.

Podemos apreciar a conexão entre o modo ywaled e a idéia de filhos como presente de Deus em outro contexto: quando Jó é informado da morte de seus descendentes, ele exclama: “ ...D' deu, D' tirou ” ( Jó 1:21). No v.2 desse mesmo capítulo lemos que "nasceram-lhe sete filhos e três filhas" ${ }^{32} \mathrm{O}$ termo utilizado é waywaldu lo.

\footnotetext{
${ }^{30}$ idem.

${ }^{31}$ Posto que "prostrou-se com o rosto em terra". Segundo Westermann, trata-se de um gesto antigo de submissão, um ato de reverência perante Deus e uma expressão física de "amen". Westermann, op. cit., p.260.

${ }^{32}$ nossa tradução.
} 
Também ao amaldiçoar o dia de seu nascimento, o autor utiliza o termo yom 'iwaled bo, desejando não ter recebido a dádiva da vida e lamentando não ter sido um aborto escondido.

O emprego da terminologia reprodutiva no ciclo de Sara e Abraão sugere o seguinte esquema geral:

Em Gn 11, Sara é estéril.

Em Gn 15, Abraão não tem semente.

Em Gn 16, nenhum dos dois tem descendência, pois Sara não deu à luz um filho a Abraão.

Em Gn 18, ambos são idosos e não podem ter filhos.

Mas há uma outra leitura possível - e biológica - dessas mesmas afirmações:

Em Gn 11: Sara não tem feto.

Em Gn 15: o filho de Abraão sairá de suas entranhas.

Em Gn 16: Sara está impedida de dar à luz por Deus.

Em Gn17: um homem de cem anos não pode gerar.

Em Gn 17: uma mulher de noventa anos não pode dar à luz.

Em Gn18: Sara está na menopausa.

Em Gn 18: Abraão está na andropausa.

Elementos de ordem física, gráficos, visíveis, contrapõem a fenomenologia humana ao caráter da ação de Deus expresso no termo $p l$ ' - milagre (18:14). Há uma didática teológica poderosa nessa contraposição: é assim que Deus age em relação a Israel.

\section{O SENTIDO DE waladNA CONCLUSÃO}

A minha conclusão é que, enquanto o termo 'aqarah - com seus sentidos de infertilidade e desenraizamento - inaugura um ciclo de esterilidade abrangente, que irá caracterizar o ciclo patriarcal como um todo, o termo walad introduz um ciclo intra-abraâmico, iniciado em Gn11:30 e concluído em Gn 21:5.

A terminologia de conotação biológica estabelece um ciclo de esterilidade e de subseqüente fertilidade, e sua importância está fundamentada no fato de 
comportar o cumprimento de uma porção da promessa divina feita a Abraão: a de seu herdeiro, filho de suas entranhas, de linhagem cognática, ou seja, de sua esposa legal, abençoada pela divindade, em sua velhice, com o dom da fertilidade.

Esse é um elemento primordial da história da promessa e da consciência israelita: Deus cumpriu sua promessa a Abraão e a Sara, contra toda sorte de empecilhos de ordem fisiológica e natural.

Retomando a linha de pensamento sobre o ciclo intra-abraâmico, na minha opinião, o caráter miraculoso do nascimento de Isaac é um evento de quilate especial na Bíblia Hebraica; não porque Isaac seja um grande herói, cuja origem é enaltecida pela esterilidade de sua mãe, mas porque seu nascimento encerra o cumprimento de uma parte da promessa divina aos ancestrais.

Nenhum outro nascimento precedido por esterilidade (nem mesmo o de Jacó, herói epônimo da nação) evoca esta afirmação.

No ciclo maior de esterilidade patriarcal estabelecido pelos sentidos do radical ' $q r$ - e que obviamente inclui também o ciclo de Abraão e Sara - a promessa divina tem por horizonte um grupo e um tempo futuros, e nenhuma parte dela é cumprida no escopo da existência dos patriarcas. Não é por acaso que a porção da promessa que é cumprida figura no capítulo 17, no qual Deus estabelece um pacto (celebrado apenas com Noé e Abraão) que determina o caráter permanente, irreversível e imutável (mas não incondicional) da vontade divina. ${ }^{33}$ Note-se também que Abraão executa com suas próprias mãos o pacto estabelecido.

Westermann observa que, no capítulo 17, todas as promessas da tradição

\footnotetext{
${ }^{33}$ Skinner, Genesis. Endinburgh: T\&T Clark, 190, pp. 297-8.

${ }^{34}$ Westermann, op. cit., p. 255.

${ }^{35}$ Segundo van Setters, duas histórias da tradição de Abraão são universalmente atribuídas à fonte sacerdotal: Gn 17 (pacto da circuncisão) e Gn 23 (a compra da gruta). E elementos temáticos característicos desses dois capítulos são encontrados em todo o Pentateuco. van Setters, Abraham in History and Tradition. New Haven: Yale University Press, 1975, p. 120. ${ }^{36}$ Westermann reconhece em Gn18:11 uma informação introduzida "entre parênteses", no curso da narrativa, composta de três sentenças circunstanciais: as duas primeiras apresentam Abraão e Sara como uma unidade ("idosos e avançados em anos"). A terceira veicula uma informação de caráter puramente fisiológico que atesta, de modo irrefutável, a impossibilidade biológica de Sara de gerar ("Sara não mais possui as regras costumeiras às mulheres"). Westermann, op. cit., p.280. Note-se que o isolamento de Sara em relação às outras mulheres casadas, aptas a gerar, é restaurado através dessa observação, que faz ecoar o contexto de Gn11:30: Gn18:11) hadal lihiot --- lah --- 'orah kenašim. (Gn11:30) 'ein --- lah --- walad.
} 
patriarcal antiga são retrabalhadas e posicionadas uma em relação à outra. ${ }^{34}$

A informação sobre a idade de Abraão e Sara enquadra o cumprimento, perfeito e pontual, da promessa no esquema genealógico. A mudança do nome indica um renascimento coerente com a expansão da promessa, que, nessa instância, consiste na introdução da noção de paternidade ("pai de muitas nações”). A continuidade intergeracional é enfatizada. A unidade Abraão e Sara é meticulosamente delineada em paralelismos e a ação de Deus em favor da unidade matriarca-patriarca é pontuada pelo termo 'olam (eterno).

A meu ver, cabe recolocar a discussão sobre a natureza da sentença “' ein lah walad', avaliando sua coerência com o estilo e a ideologia sacerdotal, que se caracteriza, inclusive, pelo emprego da terminologia reprodutiva como instrumento para focalizar a capacidade biológica individual de procriar.

Gn17:17 e 21:5 são versículos universalmente atribuídos à fonte sacerdotal. Os capítulos em questão apresentam elementos temáticos tipicamente sacerdotais: ${ }^{35}$ o fato de ser o pai - e não a mãe - a dar o nome ao filho; a circuncisão no oitavo dia; a preocupação com dados de natureza genealógica, como a idade do pai; a insistência em afirmar a paternidade de Abraão em relação a Isaac (Gn 21: 2,7).

A ênfase nos obstáculos de ordem natural em Gn 18: $11^{36}$ (idade avançada de ambos, menopausa de Sara) e a constatação óbvia de Sara sobre a abstinência sexual do casal e a idade avançada (impotência? andropausa?) de seu marido no v.12 vêm reforçar o caráter miraculoso do nascimento de Isaac.

Deve-se levar em conta também que vários elementos constitutivos dos outros relatos de esterilidade não estão presentes na esterilidade de Sara: Sara não se lamenta; não pede a Deus; Deus não ouve nem vê Sara; Deus não se compadece de Sara; Deus não abre o ventre de Sara.

A sua esterilidade - que na introdução é apresentada de forma integralmente secular - é, de fato, integralmente sacra. Ao romper seu silêncio em Gn 16:2, Sara nos explica delicadamente (hinneh $n a^{\prime}$ ) a origem, mas nunca a razão, de sua esterilidade. Para tanto, utiliza uma fórmula que não tem paralelo na Bíblia Hebraica: 'asarani miledet, ${ }^{37}$ e que denota, a um só tempo, a raiz teológica da esterilidade (oriunda de Deus, sem razão aparente) e a aceitação e conformação

\footnotetext{
${ }^{37}$ Gn 20:18 ('asor 'asar kol rehem le beit 'avimelekh), segundo Skinner e Gunkel, é uma explicação inadequada e supérflua do v.17, universalmente reconhecida como uma glosa. Skinner, op. cit., p. 320; Gunkel, Genesis. Georgia: Mercer University Press, 1997; p. 210.

${ }^{38}$ Ibid., p. 1x; Ibid, p.266.
} 
(uma modalidade de obediência) para com o desígnio divino. O fruto de seu ventre, que será criado a partir da palavra divina, também será diferente de todos os outros - anteriores e posteriores.

Com base na terminologia reprodutiva sacerdotal, e na coerência que o uso desta terminologia confere a um ciclo interno, em meio ao contexto maior da esterilidade da era patriarcal, parece-me que 'ein lah walad não é um erro de escrita e nem uma redundância. É, antes, um elemento preciso, um componente deliberado da elaboração de um ciclo, que além de assegurar o cumprimento de uma porção da promessa a Abraão, permite um movimento sutil que vai da introdução à conclusão: da descrição objetiva e fria da ausência de feto no ventre de uma mulher ao enaltecimento do poder reprodutivo de um homem de cem anos; de walad (indefinido) a bno (mais que definido - o filho dele, do patriarca).

Poderia 'ein lah walad ser uma adição editorial sacerdotal à construção javista da caracterização das matriarcas como “"aqarah”?

Embora não esteja no escopo desta pesquisa questionar a complexa questão das fontes do Pentatueco, creio ser válido enumerar algumas considerações literárias que apontam nessa direção.

Antes de tudo, o uso de arcaísmos. H.Gunkel comenta que uma das características singulares da fonte sacerdotal é a utilização de expressões raras e solenes e também de arcaísmos, ${ }^{38} \mathrm{e}$ walad, como vimos, é um arcaísmo que confere solenidade à introdução da trama em Gn11:30.

É também característico do estilo sacerdotal o emprego de referências biológicas relativas ao processo reprodutivo e o reconhecimento do ciclo menstrual como condição feminina, que enfatiza a impossibilidade de conceber segundo padrões da compreensão humana. Pode-se traçar um paralelo com a outra definição biológica que impede a concepção: a ausência de feto.

Apesar da ênfase por parte do narrador e dos protagonistas na idade avançada do casal no início da narrativa, e no ciclo menstrual, na iminência de seu desfecho, a narrativa determina que a esterilidade está na mulher, locada no processo biológico de reprodução feminino (muito embora a idade avançada do homem seja um fator cogitado).

Em minha leitura inicial do texto, antes mesmo de analisá-lo, a expressão 'ein lah walad, como definição de esterilidade, pareceu conter alguma equivalência com a definição de fertilidade, encontrada em Lv 12: 2: 'iša ki tazri 'a (mulher 
inseminada de semente ${ }^{39}$ ).É uma maneira de reduzir dois eventos cruciais da vida de uma mulher, principalmente uma mulher da Antigüidade, a um nível essencialmente biológico, reprodutivo, objetivo. Uma visão e estilo característicos da fonte sacerdotal.

Outros elementos inconfundíveis do estilo sacerdotal estão presentes no ciclo intra-abraâmico : o enquadramento de informações em estruturas genealógicas, cronológicas e contratuais, a precisão formal de estilo, o uso recorrente de expressões da abertura no desfecho ${ }^{40}$ e a composição de um ciclo temático através do emprego de terminologia memorável ${ }^{41}$.

${ }^{39}$ nossa tradução.

${ }^{40}$ Skinner, op. cit., p. 298.

${ }^{41}$ Fazendo-se uma breve observação sobre a situação atual da discussão das fontes, tem-se os seguintes dados: A lista genealógica linear em Gn11:10-26 é universalmente atribuída à fonte sacerdotal. Os versos 28-30 são atribuídos à fonte javista. Gunkel, op. cit., pp.162-163; Skinner, op. cit., pp.235-39; von Rad, op. cit., p.154. No entanto, van Setters discorda desta atribuição. Para ele, todos os versículos de Gn 11 formam uma unidade sacerdotal. Segundo ele, o v.28 pressupõe a informação fornecida no v.27, e o mesmo ocorre em relação aos vv. 31 e 28. Os mesmos referenciais e terminologia são repetidos em Gn 12: 4-5, claramente sacerdotal. van Setters, op. cit., p.225. Apesar de esse autor não fazer nenhuma observação sobre Gn 11:30, ele o engloba na unidade sacerdotal. Gn 16:1 ('ešet 'avram lo'yaldah lo ben) é atribuído à fonte sacerdotal, parcialmente por causa do termo 'eset, e porque funciona como introdução à infertilidade de Sara, que na fonte javista foi antecipada em 11:30. Skinner, op. cit., p.285. 
Suzana Chwarts é arqueóloga bíblica e professora de Estudos Bíblicos na área de Língua Hebraica, Literatura e Cultura Judaicas da Faculdade de Filosofia, Letras e Ciências Humanas da USP.

\section{BIBLIOGRAFIA CONSULTADA}

\section{TEXTOS BÍBLICOS, TRADUÇÕES E DICIONÁRIOS:}

A Bíblia de Jerusalém. São Paulo: Sociedade Bíblica Católica Internacional e Paulus, 1985.

BEN YEHUDA, Eliezer. A complete dictionary of ancient and modern Hebrew, vols.I XIII. Jerusalem: Hemda and Ehud Benyehuda, 1951.

BROWN, F.; DRIVER,S.R. e BRIGS, C.. A Hebrew and English lexicon of the Old Testament. Oxford: Clerndon Press, 1972.

BROWNING, W.R.F.. A dictionary of the Bible. Oxford: Oxford University Press, 1996.

CLARK, Matityahu. Etymological dictionary of Biblical Hebrew. Jerusalem: Feldheim Publishers, 1999.

CLINES, David J.A.. (ed.). The dictionary of classical Hebrew, vols. I- V . Sheffield: Sheffield Academic Press, 1993.

HERCZEG, Y.I.; PETROFF, Y; KAMENETSK, Y.. The Torah: with Rashi's commentary translated, annotated and elucidated. The ArtScroll Series. New York: Mesorah Publications, s.d.

KOEHLER, Ludwig e BAUNGARTEN, Walter. Lexicon in Veteris Testamenti Libros. Leiden: E.J. Brill, 1985.

MONLOUBOU, L. e DU BUIT, F.M.. Dicionário bíblico universal. Petrópolis: Vozes, 1996.

SCHÖKEL, Luis Alonso. Dicionário bíblico hebraico-português. São Paulo: Paulus, 1997.

SHOSHAN, Avraham Even. ha milon ha 'ivri . Jerusalem: Kiryat Sefer, 1991.

Torá - a lei de Moisés. São Paulo: Editora Sêfer, 2001. 


\section{ESTUDOS BÍBLICOS:}

ALTER, Robert. The art of Biblical narrative. New York: Basic Books Publishers, 1981.

. Genesis. New York: W.W. Norton \& Company, 1996.

• "Imperativos Bíblicos e Jogo Literário" e "Especificação Narrativa e Sentido

literal na Bíblia Hebraica", em Simpósio de cultura Oriental e cultura Ocidental: Projeções, Rifka Berezin (coord.). Universidade de São Paulo; Faculdade de Filosofia, Letras e Ciências Humanas; Departamento de Línguas Orientais. São Paulo, 1990.

ALTER, Robert e Kermode, Frank (orgs.). Guia literário da Bíblia, trad. Raul Fiker. São Paulo: Fundação Editora da Unesp, 1997.

BRENNER, Athalya. The Israelite woman: social role and literary type in Biblical narrative. Sheffield: JSOT Press, 1985.

BRIGHT, John. História de Israel, trad. Euclides Carneiro da Silva. São Paulo: Paulus, 1978.

CALLAWAY, Mary. Sing, o barren one - a study in comparative midrash. Atlanta: Scholars Press, 1986.

CASPI, Moshe. "mosivi 'aqeret habayt 'em habanim smehah” em Beit Miqrah, vol. 82 - July -Setpember. Jerusalem: Israel Society for Biblical Research: 1980.

CHOURAQUI, André. The people and the faith of the Bible, trad. William V. Gugli.

Amherst: University of Massachusetts Press, 1975. . No Princípio; trad. Carlito Azevedo. Rio de Janeiro: Imago, 1995.

DE VAUX, Roland. Ancient Israel - social institutions \& religious institutions, vols.I, II, trad. Darton, Longman \&Todd Ltd. New York: McGraw-Hill Book Company, 1965.

FISHBANE, Michael. Biblical text and texture. Oxford: Oneworld, 1989.

. "Accusations of Adultery: A Study of Law and Scribal Practice in Numbers 5:11-31", em Women of the Bible, Alice Bach (ed.). London: Routledge, 1999.

FOKELMANN, J. P.. Narrative art in Genesis: specimens of stylistic and structural analysis. Amsterdan: Van Gorcum, 1975.

. “Genesis”, em Guia literário da Bíblia, Robert Alter e Frank Kermode (orgs.), trad. Raul Filker. São Paulo: Fundação Editora da Unesp, 1997.

GUNKEL, Hermann. Genesis, trad. Mark E.Biddle. Macon, Georgia: Mercer University Press, 1997.

LEVINE, Baruch A.. Leviticus The JPS Torah Commentary. Philadelphia: The Jewish Publication Society, 1989. 
. "The Epilogue to the Holiness Code", em Neusner, Jacob; Levine, Baruch A.;

Frerichs, Ernest S. (eds.). Judaic perspectives on Ancient Israel. Philadelphia: Fortress Press, 1987.

MILGROM, Jacob. Leviticus 1-16 - The Anchor Bible. New York: Doubleday.

PEDERSEN, Johs.. Israel, It's life and culture I-II. London: Oxford University Press, 1926.

RUETHER, Rosemary Radford (ed.). Religion and sexism - Images of women in Jewish and Christian traditions. New York: Simon and Schuster, 1974.

SARNA, Nahum M.. Understanding Genesis - the world of the Bible in the light of history. New York: Schocken Books, 1966.

. Genesis - The JPS Commentary. Philadelphia: The Jewish Publication Society, 1989.

SKINNER, John. Genesis - the international critical commentary. Edinburgh: T.\&T. Clark, 1910.

SPEISER, E.A.. Genesis - the Anchor Bible. Garden City: Doubleday,1964.

VAN SETTERS, John. Abraham in history and tradition. New Haven: Yale University Press, 1975.

. "The problem of childlessness in near eastern law and the patriarchs of Israel", em Journal of biblical literature 87 (1968),108-401.

VON RAD, Gerhard.Genesis. Philadelphia: Westminster Press 1961.

WESTERMANN, Claus.Genesis 12-36 - a commentary, trad.John J. Scullion S.J.. Minneapolis: Augsburg Publishing House, 1981.

. Genesis 37-50 - a commentary, trad.John J. Scullion S.J.. Minneapolis: Augsburg Publishing House, 1981. 
Abstract: This research focuses on the phrase 'ein lah walad in Gen $11: 30$, as it has been interpreted by ancient and modern exegetes as redundant to 'aqarah, or still as a scribal mistake.

Through literary and philological analysis, I identified an inner cycle within the wider Abraham and Sara's cycle of sterility - that stresses both Sara's and Abraham's biological impossibility of conceiving.

This inner cycle is framed by reproductive terminology such as walad ( Gen 11:30) - ywaled (Gen 17:17 ) - behiwwaled (Gen 21:5 ) - terms that are thematically, semantically and phonetically, interconnected and define a beginning and a closure to the cycle.

The choice of these words reveals an accurate precision that confers contours and coherence to this inner cycle that begins with Sara's absence of a fetus - an inexorable impossibility - and ends with Isaac's miraculous birth at the improbable late age of his father.

This birth stands for the portion of the divine promise fulfilled within the lives of both the matriarch and patriarch, and is depicted accordingly in solemn language, unlike the usual nolad employed for Ismael's birth. The logic of this cycle validates the employment of walad as an archaism, a special and accurate term that confers stability to the introduction and acts as a champs de force within the narrative; and therefore restores the impact - probably the original intention - of the sentence 'ein lah walad in introducing Sarah into the narrative, with its properties of infirmity, and insubstantiality, unlike the very concrete yeled (child).

This study also encompasses the discussion whether Gen11:28-30 comes as a Yawistic interpolation in the genealogy of Gen 11 or it is to be attributed to $P$.

Key words : Hebrew Bible, Matriarchs, Divine Promise, Sterility . 
